Biochim Biophys Acta. 2009 October ; 1790(10): 1049-1058. doi:10.1016/j.bbagen.2009.02.005.

\title{
Klotho and aging
}

\author{
Makoto Kuro-o, M.D., Ph.D. \\ Department of Pathology, The University of Texas Southwestern Medical Center at Dallas, 6000 \\ Harry Hines Blvd., Dallas, TX 75390-9072, U.S.A. Phone: +1-214-648-4018, Fax: +1-214-648-4070, \\ E-mail: makoto.kuro-o@utsouthwestern.edu
}

\section{Abstract}

The klotho gene encodes a single-pass transmembrane protein that forms a complex with multiple fibroblast growth factor (FGF) receptors and functions as an obligatory co-receptor for FGF23, a bone-derived hormone that induces negative phosphate balance. Defects in either Klotho or Fgf 23 gene expression cause not only phosphate retention but also a premature-aging syndrome in mice, unveiling a potential link between phosphate metabolism and aging. In addition, the extracellular domain of Klotho protein is clipped on the cell surface and secreted into blood stream, potentially functioning as an endocrine factor. The secreted Klotho protein has a putative sialidase activity that modifies glycans on the cell surface, which may explain the ability of secreted Klotho protein to regulate activity of multiple ion channels and growth factors including insulin, IGF-1, and Wnt. Secreted Klotho protein also protects cells and tissues from oxidative stress through a mechanism yet to be identified. Thus, the transmembrane and secreted forms of Klotho protein have distinct functions, which may collectively affect aging processes in mammals.

\section{Keywords}

Klotho; FGF23; phosphate; vitamin D; sialidase; TRPV5

\section{Introduction}

In Greek mythology, three goddesses determine life span of every mortal by controlling the thread of life. They are Klotho, Lachesis, and Atropos who spins, measures, and cuts the thread of life, respectively. The klotho gene, named after the spinner, was identified in 1997 as a gene mutated in the klotho mouse, which displays extremely shortened life span with multiple disorders resembling human premature-aging syndromes [1]. The klotho mouse was serendipitously generated as a by-product during the process of making transgenic mice by conventional pronuclear microinjection of a transgene [2]. Since transgene integration occurs randomly in the mouse genome, the transgene can accidentally disrupt an endogenous mouse gene(s) around the integration site (insertional mutation), which occasionally results in unexpected phenotypes. The klotho mouse was one of the transgenic mouse lines that did not express the transgene and therefore was supposed to be of no use. However, it displayed multiple aging-like phenotypes when homozygous for the transgene due to insertional mutation of the transgene. Analysis of the klotho mouse genome revealed that $~ 10$ copies of the transgene

Correspondence to: Makoto Kuro-o.

Publisher's Disclaimer: This is a PDF file of an unedited manuscript that has been accepted for publication. As a service to our customers we are providing this early version of the manuscript. The manuscript will undergo copyediting, typesetting, and review of the resulting proof before it is published in its final citable form. Please note that during the production process errors may be discovered which could affect the content, and all legal disclaimers that apply to the journal pertain. 
were integrated in tandem at a single locus on chromosome 5 and disrupted a promoter region of an unknown gene, which later was identified as the klotho gene [1].

The klotho gene is composed of 5 exons [3,4] and encodes a type-I single-pass transmembrane protein (1,014-amino acid-long). The intracellular domain is short (10-amino acid-long) and has no known functional domains. The extracellular domain is composed of two domains with weak homology, termed KL1 and KL2. Each domain has homology to Family 1 glycosidases, including lactose-phlorizin hydrolase of mammals and $\beta$-glucosidases of bacteria and plants $[1,5]$. These enzymes have exoglycosidase activity that hydrolyzes $\beta$-glucosidic linkage in saccharides, glycoproteins, and glycolipids. However, recombinant Klotho protein did not have $\beta$-glucosidase-like enzymatic activity, probably because critical amino acid residues in putative active centers of Klotho protein diverge from those conserved throughout the $\beta$-glucosidase family of enzymes [1,5].

The klotho gene is expressed in limited tissues and cell types. The highest expression is observed in distal convoluted tubules in the kidney and choroid plexus in the brain [1]. Lower expression is detected in pituitary gland, brain, parathyroid gland [6], pancreas, ovary, testis, placenta, skeletal muscle, urinary bladder, colon [1], inner ear [7], and breast epithelial cells [8]. Klotho gene expression is strongly suppressed in the klotho mouse due to the insertional mutation at the $5^{\prime}$ flanking region of the klotho gene [1]. Thus, the klotho mouse is not a null but a severe hypomorph strain. A null strain for the klotho gene was later generated by conventional gene targeting and exhibited aging-like phenotypes identical with those observed in the original klotho mouse [9]. Therefore, the Klotho ${ }^{-1-}$ mouse and the original klotho mouse are collectively described as Klotho-deficient mice in this review.

\section{Klotho-deficient mice}

Klotho-deficient mice are almost indistinguishable from their wild-type and heterozygous littermates in appearance and growth up to 3 weeks of age. Thereafter, they stop growing and hardly gain body weight until they die prematurely around 8-9 week of age. Although they display multiple pathologies resembling human aging as described below, a specific cause of death is not clear, because each of these pathologies appears not fatal by itself [1].

\subsection{Hypogonadism}

Klotho-deficient mice have atrophic external and internal genital organs in both sexes. They never become sexually mature and are infertile. Testis is extremely atrophic and contains no mature sperms. Maturation of spermatocytes is halted at the pachytene stage. Ovary contains only primary or secondary follicles and no Graafian follicles or corpus lutea [1]. Although Klotho expression is detectable in ovary, the impaired follicle maturation in Klotho-deficient mice is not due to a defect in the ovary but caused by a defect in pituitary and/or hypothalamus function (hypogonadotropic hypogonadism), because 1) serum LH and FSH levels in Klothodeficient mice are lower than those in wild-type mice, 2) maturation of follicles and growth of uteri can be resotred by gonadotropin treatment in Klotho-deficient mice, and 3) ovaries from Klotho-deficient mice function normally when transplanted into wild-type female mice [10]. These observations suggest that Klotho may be involved in the regulation of gonadotropin and gonadotropin releasing hormone production/secretion in the pituitary gland and hypothalamus.

\subsection{Premature thymic involution}

The thymus of Klotho-deficient mice develops normally up to 3-4 weeks of age, and then quickly reduces its size until it becomes barely detectable by $6-9$ weeks of age [1]. Thymopoietic insufficiency in Klotho-deficient mice is not due to an intrinsic defect in lymphohematopoietic progenitors, because hematopoietic stem cells from Klotho-deficient 
mice can differentiate into normal lymphoid cells when transplanted into SCID mice [11]. It is due to a defect in thymic epithelial cells that support proliferation and survival of thymocytes. This pathophysiology is similar to that observed in thymic involution associated with normal aging process. Importantly, injection of KGF (keratinocyte growth factor, a.k.a. FGF7), which induces proliferation of thymic epithelial cells, improves thymopoesis and restores thymic degeneration not only in Klotho-deficient mice but also in aged wild-type mice [11].

\subsection{Ectopic calcification}

Extensive ectopic calcification in various soft tissues is observed in Klotho-deficient mice. It occurs most prominently in gastric mucosa, trachea, renal tubules, and small arteries in the kidney as well as larger arteries including renal arteries and aorta. Vascular calcification occurs in the media without concomitant intimal thickening or accumulation of foam cells. Thus, these vascular changes are not typical atherosclerosis but resemble Mönckeberg-type arteriosclerosis often observed in the aged as well as in patients with diabetes and chronic kidney disease in humans [1]. Ectopic calcification and vascular calcification in Klotho-deficient mice may be secondary to elevated blood calcium, phosphate, and vitamin D levels $[9,12]$. The mechanism by which Klotho deficiency causes impaired calcium/phosphate metabolism is discussed in detail later.

\subsection{Impaired bone mineralization}

Klotho-deficient mice have osteopenia [1,13]. Cortical bone thickness of femur, tibia, and vertebrae is decreased by $20-40 \%$ when compared with wild-type mice. Histomorphometric analysis of the bone shows that osteopenia in Klotho-deficient mice is accompanied by significant reduction in both bone formation and resorption. The decrease in bone formation exceeds that in bone resorption, resulting in a net bone loss with low bone turnover. This pathophysiology is similar to that observed in senile osteoporosis in the aged but distinct from post-menopausal osteoporosis in women triggered by estrogen withdrawal, because postmenopausal osteoporosis is primarily caused by increased bone resorption due to increased osteoclast number and function, which results in high bone turnover. Although cortical bones are reduced in Klotho-deficient mice, they have paradoxically increased trabecular bones in vertebrae and the metaphysis of tibia and femur [13-15]. Although the mechanism by which Klotho deficiency affects cortical and trabecular bones in a different way remains to be determined, dysregulation of Wnt signaling pathway may be involved, which is discussed later.

\subsection{Skin atrophy}

The skin of Klotho-deficient mice is thin and atrophic. Histological examination shows reduced number of hair follicles and reduced thickness of the dermal and epidermal layers. No subcutaneous fat is observed. These findings are similar to those observed in senile atrophoderma in the aged [1].

\subsection{Pulmonary emphysema}

Histology of the lung of Klotho-deficient mice is indistinguishable from that of wild-type littermates up to 2 weeks of age, by which time the lung becomes mature. Around 4 weeks of age, lungs of Klotho-deficient mice undergo progressive emphysematous changes including destruction of alveolar walls and enlargement of air spaces [1]. In addition to the histological changes, the respiratory function of Klotho-deficient mice is consistent with pulmonary emphysema characterized by increased compliance and expiratory time [16]. Aging and smoking have been identified as the two major risk factors for pulmonary emphysema. A mathematical model suggests that the pattern of alveolar destruction in Klotho-deficient mice is consistent with a random destruction caused by a systemic factor(s) rather than a correlated 
destruction caused by a local factor(s) such as smoking [17]. Thus, the lung of Klotho-deficient mice may represent aging-related pulmonary emphysema.

\subsection{Neurodegeneration}

Klotho-deficient mice have impairment in cognitive function measured by novel-object recognition and conditioned-fear tests when compared with wild-type mice [18]. The cognition impairment in Klotho-deficient mice is associated with increased number of apoptotic cells and increased levels of oxidized lipid and DNA in the hippocampus. Furthermore, treatment of Klotho-deficient mice with an antioxidant $\alpha$-tocopherol improves cognition impairment and reduces oxidative damage and apoptotic cells in hippocampus, suggesting that Klotho may function as a neuroprotective factor through preventing neurons from oxidative damage. In addition, Klotho-deficient mice exhibited degenerative changes of anterior horn cells (AHCs) in the spinal cord. This is similar to the finding observed in patients with amyotrophic lateral sclerosis (ALS). AHCs of Klotho-deficient mice show significant decrease in cytoplasmic RNA, ribosomes, and rough endoplasmic reticulum and accumulation of neurofilaments as those of ALS patients [19]. Recent studies have indicated that increased oxidative stress may be a common mechanism behind many neurodegenerative disorders including Alzheimer's disease, Parkinson's disease, and ALS [20]. The ability of Klotho protein to alleviate oxidative stress (discussed later) may contribute to the neuroprotective properties of Klotho.

\subsection{Hearing loss}

The klotho gene is expressed in the stria vascularis and spiral ligament of the inner ear. Although Klotho-deficient mice have no morphological abnormalities in the inner ear, they have significantly higher threshold for auditory brainstem response than wild-type mice, indicating the existence of hearing disorder [7]. Although function of Klotho in the inner ear is not known, it is possible that Klotho protein may be involved in the electrolyte homeostasis of endolymph in the cochlear duct through its activity that regulates ion channels.

\subsection{Blood chemistry}

Klotho-deficient mice have higher levels of serum phosphorus, calcium, and active vitamin D (1,25-dihydroxyvitamin $\mathrm{D}_{3}$ ) [9] and lower levels of serum glucose [21] than wild-type mice. Importantly, these abnormal measures are observed as early as 2 weeks of age before Klothodeficient mice develop visible aging-like phenotypes. The mechanism for the abnormal blood chemistry is closely associated with Klotho protein function and discussed later in detail.

\subsection{Phenotypes not observed in Klotho-deficient mice}

All these phenotypes appear in every Klotho-deficient mouse with $100 \%$ penetrance. Remarkably, several aging-like phenotypes are observed in tissues that do not express Klotho endogenously, suggesting that a humoral factor(s) mediates Klotho protein function. As negative findings, there is no report so far indicating that Klotho-deficient mice have an increased incidence of malignant tumors or increased amyloid plaques or neurofibrillary tangles in the brain, which are common features of aging. It is possible that they might die too early (around 2 months of age) to develop these diseases. Although there are differences between pathophysiology observed in Klotho-deficient mice and that in natural aging, Klothodeficient mice have been used as one of the best characterized mammalian models for premature-aging syndromes that manifests multiple aging-like phenotypes in a single individual. 


\section{Klotho-overexpressing transgenic mice}

Two independent transgenic mouse lines were established that over-expressed the transmembrane form of Klotho protein under the control of a ubiquitous promoter (human elongation factor-1 $\alpha$ promoter) [1]. One of them (EFmKL46) expressed exogenous Klotho in every tissue so far examined, while the other line $(E F m K L 48)$ expressed the transgene only in several tissues including brain and testis, but not in the kidney, probably due to a position effect of the transgene integration site. Despite the lack of Klotho in the kidney where endogenous Klotho expression is most abundant, the EFmKL48 allele was able to rescue the aging-like phenotypes when introduced into the Klotho-deficient mice, indicating that expression in the kidney may not be essential for Klotho protein function. This is consistent with the notion that a humoral factor(s) may mediate Klotho protein function. Both EFmKL46 and EFmKL48 transgenic mice appeared normal and lived 20-30\% longer on average than wild-type mice [22]. Life span extension observed in these mice is not as robust as that observed in $d w a r f$ mice carrying defects in the somatotroph axis [23-25] and remains to be confirmed under different housing conditions. Nonetheless, the klotho gene is considered as one of the aging-suppressor genes identified in mammals that extends life span when over-expressed and causes a premature-aging syndrome when disrupted. Since food consumption of the transgenic mice is not decreased, it is unlikely that they lived longer simply because they ate less and voluntarily restricted calorie intake [22]. As discussed later, the transgenic mice that over-express Klotho exhibit significant resistance to oxidative stress associated with moderate resistance to insulin/ IGF-1, which may partly explain why these mice live longer than wild-type mice.

Another set of transgenic mice that over-express Klotho was established using an inducible promoter (mouse metallothionein-1 promoter) to drive expression of the transmembrane form of Klotho [26]. Klotho-deficient mice carrying this inducible transgene largely depend on zinc water feeding for Klotho expression. When left untreated, these mice develop premature-aging symptoms as Klotho-deficient mice do. When given $25 \mathrm{mM} \mathrm{ZnSO}_{4}$ solution as a drinking water, these mice express exogenous Klotho primarily in the gastrointestinal tract, which rescues all the aging-like phenotypes. More importantly, many advanced aging-like phenotypes are rescued when Klotho expression is induced by zinc feeding even after they have already developed multiple aging-like phenotypes. In addition, reduction of Klotho expression by zinc removal in these rescued Klotho-deficient mice rapidly induces several aging-like phenotypes including ectopic calcification and pulmonary emphysema. These observations indicate that reduction of Klotho expression in adulthood can be a cause of several aging-like disorders and that Klotho replacement may be useful for the treatment of these disorders. In fact, Klotho was recently identified as one of the genes whose expression was significantly down-regulated with age in the brain of rodents and primates (rhesus monkey) [27].

\section{Klotho protein functions}

The klotho gene encodes a single-pass transmembrane protein. The extracellular domain of Klotho protein is clipped just above the plasma membrane by membrane-anchored proteases ADAM10 and ADAM17 to generate a secreted form of Klotho protein [28]. In fact, the entire Klotho ectodomain is detectable as a single peptide in the blood, urine, and cerebrospinal fluid $[22,29]$. Thus, Klotho protein exists in two forms. One is the transmembrane form expressed primarily in renal tubular cells, and the other is the secreted form circulating in the blood (Fig. $1)$.

In addition to these two forms of Klotho protein, mRNA encoding another form of secreted Klotho protein is generated through an alternative splice donor site in the $3^{\text {rd }}$ exon. The resulting mRNA encodes a putative secreted protein that consists of the KL1 domain alone and lacks 
the KL2, transmembrane, and intracellular domains [3,4]. However, the truncated ectodomain (KL1 domain only) has not been detected in the blood. Thus, this review focuses on function of the two forms of Klotho protein: the transmembrane form and the secreted form with the entire extracellular domain.

\subsection{Function of the transmembrane form of Klotho}

4.1.1. Regulation of phosphate metabolism-The blood phosphate level is determined by counterbalance between dietary intake from intestine, mobilization from bone (the major reservoir of calcium and phosphate in the body), and excretion from kidney into urine [30]. Phosphate metabolism is regulated by several endocrine factors. Vitamin D and parathyroid hormone (PTH), which have been extensively studied as endocrine factors that regulate calcium metabolism [31], are also involved in phosphate metabolism. The active form of vitamin $\mathrm{D}\left(1,25\right.$-dihydroxyvitamin $\left.\mathrm{D}_{3}\right)$ is synthesized in kidney and acts on intestine to increase absorption of dietary calcium and phosphate. It also acts on bone to stimulate osteoclastogenesis and promote mobilization of calcium and phosphate from the reservoir, thereby increasing blood levels of both calcium and phosphate. PTH acts on kidney to promote both vitamin $\mathrm{D}$ synthesis and phosphaturia (phosphate excretion into urine). As a result, unlike vitamin D, PTH can selectively increase blood calcium levels without concomitant increase in blood phosphate levels [32].

Recent studies have identified FGF23 as a novel endocrine factor that lowers blood phosphate and vitamin D levels [33-35]. FGF23 is secreted from osteocytes in response to high blood phosphate and vitamin D levels [36]. FGF23 acts on kidney to 1) induce phosphaturia by suppressing Na-phosphate cotransporters in renal tubular cells and 2) counter-regulate vitamin D by down-regulating expression of the Cyp27b1 gene encoding $1 \alpha$-hydroxylase, the enzyme that synthesizes 1,25-dihydroxyvitamin $\mathrm{D}_{3}$ from its inactive precursor (25-hydroxyvitamin $\mathrm{D}_{3}$ ), and by up-regulating expression of the Cyp24 gene encoding 24-hydroxylase, the enzyme that inactivates 1,25-dihydroxyvitamin $\mathrm{D}_{3}[31]$. As a result, FGF23 reduces serum 1,25dihydroxyvitamin $\mathrm{D}_{3}$, which in turn reduces phosphate absorption from intestine. Thus, FGF23 induces a negative phosphate balance by functioning as a phosphaturic hormone as well as a counter-regulatory hormone for vitamin D [35,37,38].

FGF23 was originally identified as a gene mutated in patients with autosomal dominant hypophosphatemic rickets (ADHR) [34]. ADHR patients carry gain-of-function mutations in the FGF23 gene that confer resistance to proteolytic inactivation of FGF23 protein and show elevated blood FGF23 levels, leading to hypophosphatemia and a defect in bone mineralization due to phosphate wasting. In contrast, loss-of-function mutations in the FGF23 gene cause hyperphosphatemia and hypervitaminosis $\mathrm{D}$ associated with ectopic calcification in various soft tissues and blood vessels as observed in Fgf23 knockout mice [39] and patients with familial tumoral calcinosis [40]. Besides these predictable phenotypes, FGF23-deficient mice develop multiple aging-like phenotypes that are almost identical with those observed in Klothodeficient mice. These observations indicate that FGF23 and Klotho may function in a common signal transduction pathway.

The identity of FGF23 receptor was not clear because any known FGF receptors had extremely low affinity to FGF23 in vitro [41,42], suggesting the existence of a co-factor(s) that increases affinity of FGF23 to FGF receptor(s) in its target organ(s). In fact, the transmembrane Klotho protein was shown to form a complex with several FGF receptor isoforms (FGFR-1c, -3c, and $-4)$ on the cell surface and significantly increased their affinity to FGF23. Namely, Klotho functions as an obligatory co-receptor for FGF23 [43]. This finding was later confirmed by an independent study [44]. The fact that FGF23 requires Klotho for binding to FGF receptors explains why Klotho-deficient mice and FGF23-deficient mice have identical phenotypes. In addition, kidney-specific expression of Klotho explains why FGF23 can identify kidney as its 
major target organ among many organs that express FGF receptors. Thus, the novel bonekidney endocrine axis mediated by FGF23 and Klotho has emerged as the primary mechanism for endocrine regulation of phosphate and vitamin D metabolism.

The fact that Klotho functions as an obligatory co-receptor for FGF23 indicates that organs that express Klotho are potential target organs for FGF23, because most tissues express one or more FGF receptor isoforms. The parathyroid gland is one of the few organs that express Klotho endogenously and was recently identified as a target organ of FGF23 [6]. FGF23 suppresses expression and secretion of PTH in parathyroid glands [6,45]. Because PTH promotes vitamin D biosynthesis in the kidney, this novel bone-parathyroid endocrine axis mediated by FGF23 and Klotho further enhances the activity of FGF23 as a counter-regulatory hormone against vitamin D. Of note, vitamin D induces FGF23 expression in the bone through activating vitamin D receptor [46]. Thus, multiple feedback loops mediated by Klotho and FGF23 are involved in the endocrine regulation of phosphate and vitamin D metabolism (Fig. 2).

Because serum vitamin D promotes absorption of dietary phosphate and calcium from intestine, elevated vitamin D levels can be a cause of hyperphosphatemia and hypercalcemia in Klothodeficient mice and FGF23-deficient mice. Elevation of both calcium and phosphate levels in the blood leads to a significant increase in the calcium phosphate product $(\mathrm{Ca} \times \mathrm{P})$, which is a predisposition to ectopic calcification of blood vessels and soft tissues. Importantly, not only ectopic calcification but also many other aging-like phenotypes observed in FGF23-deficient and Klotho-deficient mice, including hypogonadism, hypoglycemia, pulmonary emphysema, and atrophy of skin, muscle, and thymus, are rescued by low phosphate diet or by low vitamin $\mathrm{D}$ diet or by ablating vitamin $\mathrm{D}$ activity through disruption of the vitamin $\mathrm{D}$ receptor gene [47] or the $1 \alpha$-hydorxylase gene [9,48-51]. Of note, high vitamin D by itself can trigger apoptosis and potentially cause tissue atrophy [52]. These observations indicate that the aginglike phenotypes in FGF23-deficient mice and Klotho-deficient mice are primarily caused by toxicity of excess phosphate and/or vitamin D. It should be noted that low phosphate diet further increases the already elevated serum vitamin $\mathrm{D}$ and calcium levels, but still can rescue aginglike phenotypes in FGF23-deficient mice [51]. Therefore, it is phosphate, but not vitamin D nor calcium, that is responsible for the aging-like phenotypes. It is likely that low vitamin D diet or disruption of the vitamin $\mathrm{D}$ receptor gene or $1 \alpha$-hydorxylase gene rescue aging-like phenotypes through solving phosphate retention by ablating vitamin $\mathrm{D}$ action. It remains to be determined whether hypervitaminosis $\mathrm{D}$ is a prerequisite for phosphate retention to cause multiple aging-like phenotypes These observations also suggest a novel concept that phosphate metabolism may participate in the regulation of aging.

4.1.2. Endocrine FGFs and Klothos-FGF23 belongs to the FGF19 subfamily in the FGF ligand superfamily. The FGF19 subfamily consists of FGF15, FGF19 (the human ortholog of mouse FGF15), FGF21, and FGF23 [53]. These FGFs are also collectively called as endocrine FGFs because they function as hormones unlike the other FGFs that function as paracrine and/ or autocrine factors. Recent studies have unveiled novel endocrine axes mediated by these endocrine FGFs. Briefly, FGF19 (the human ortholog of FGF15) is secreted from intestinal epithelial cells in response to bile acid released upon feeding [54]. FGF15/19 acts on liver to reduce bile acid synthesis through suppressing expression of the Cyp $7 a 1$ gene that encodes the rate-limiting enzyme for bile acid synthesis [54]. In addition, FGF15/19 acts on gallbladder to induce bile acid filling and limit bile acid release into intestine [55]. Thus, FGF15/19 is involved in a postprandial negative feedback loop that regulates bile acid synthesis and release. In contrast to FGF15/19, FGF21 is secreted from liver upon fasting and acts on adipocytes to promote glucose uptake [56] and lipolysis [57]. Like FGF23, FGF15/19 and FGF21 require a co-receptor for binding to their cognate FGF receptors with high affinity. The co-receptor is $\beta$ Klotho, a Klotho-related protein sharing $\sim 40 \%$ amino acid sequence identity [58]. $\beta$ Klotho is expressed predominantly in the liver and white adipose tissue, while Klotho is expressed 
mainly in the kidney. $\beta$ Klotho also forms a complex with several FGF receptor isoforms and significantly increases their affinity to FGF15/19 and FGF21 [59]. These findings explain why mice defective in $\beta$ Klotho [60], FGFR4 [61], or FGF15 [54] all develop increased bile acid synthesis. Thus, the Klotho gene family (Klotho and $\beta$ Klotho) could have evolved in the regulation of endocrine FGFs. The emerging concept is that tissue-specific expression of the Klotho gene family members determines target organs of the endocrine FGFs. This may represent a new mechanism for regulating ligand-receptor interaction in target organs [6264].

\subsection{Function of the secreted form of Klotho}

The transmembrane form of Klotho protein functions as a co-receptor for FGF23 when it forms a complex with FGF receptors on the cell surface. However, the secreted from of Klotho protein cannot function as a soluble receptor for FGF23 because Klotho protein alone cannot bind to FGF23 with high affinity [43], suggesting that the secreted Klotho protein may have function independent of FGF23. The secreted Klotho protein (Klotho ectodomain) has homology to the family 1 glycosidases that cleave glycosidic bonds in sugars, glycolipids, and glycoproteins. Recombinant Klotho ectodomain protein was reported to have weak $\beta$-glucuronidase activity in vitro [65], although the physiological significance of enzymatic activity of Klotho protein was not known. It has become clear recently that the secreted Klotho protein has putative sialidase activity [66] and is involved in the removal of terminal sialic acids from sugar chains of multiple cell-surface glycoproteins to alter their activity and/or cell-surface abundance. Thus, the secreted Klotho protein has emerged as a novel endocrine regulator of glycoprotein function on the cell surface.

4.2.1. Regulation of ion channel activity-The extracellular domain of Klotho protein functions as a potent activator of the Transient Receptor Potential ion channels TRPV5 and TRPV6 [67]. TRPV5 and TRPV6 are calcium channels expressed predominantly in renal tubular cells and duodenal epithelial cells, respectively, and responsible for the $\mathrm{Ca}^{2+}$ entry in the transcellular $\mathrm{Ca}^{2+}$ (re)absorption in the kidney and intestine [68]. The secreted Klotho protein, when added to the culture medium of HEK293 cells expressing TRPV5, increased the $\mathrm{Ca}^{2+}$ influx and the amount of cell-surface TRPV5. The Klotho-induced retention of TRPV5 on the plasma membrane was associated with modification of the glycans of TRPV5. However, it is unlikely that Klotho removed glucuronic acids from TRPV5 glycans by its weak $\beta$ glucuronidase activity, because typical N-linked glycans of mammalian glycoproteins do not have glucuronic acids. Endogenous sugar substrates for Klotho and the mechanism by which glycan modification alters cell-surface abundance of TRPV5 remained unclear.

It has recentlybeen shown that Klotho increases surface abundance of TRPV5 by removing particular terminal sialic acids on TRPV5 from their glycan chains. Typical N-linked glycans have sialic acids on their ends. Removal of the terminal sialic acids by secreted Klotho protein exposes underlying galactose or disaccharide $N$-acetyllactosamine. These sugars are ligands for galectin-1, a lectin (a sugar-binding protein) abundant in the extracellular matrix. Binding of TRPV5 to galectin-1 tethers TRPV5 on the cell surface and prevents its endocytosis, resulting in accumulation of the functional channel on the plasma membrane (Fig. 3) [66]. This action of Klotho represents a novel mechanism for regulation of the activity of cell-surface glycoproteins.

Recently, the transmembrane form of Klotho was reported to bind $\mathrm{Na}^{+}, \mathrm{K}^{+}$-ATPase $\alpha 1$ subunit and increased its cell-surface amount in response to a reduction of extracellular $\mathrm{Ca}^{2+}$ concentration [69]. Although it is unknown whether Klotho modifies sugar chains of $\mathrm{Na}^{+}$, $\mathrm{K}^{+}$-ATPase $\alpha 1$ subunit as it does those of TRPV5, Klotho may be able to regulate trafficking of multiple ion channels through modifying their sugar chains. 
4.2.2. Suppression of insulin/IGF-1 signaling-Klotho-deficient mice are hypoglycemic and extremely sensitive to insulin [21,47]. In contrast, Klotho-overexpressing transgenic mice are moderately resistant to insulin and IGF-1, although they maintain normal fasting blood glucose levels and are not diabetic [22]. These observations suggest that Klotho may inhibit the insulin/IGF-1 signaling pathway. In fact, secreted Klotho protein has an activity that inhibits insulin- and IGF-1-induced autophosphorylation of insulin receptor and IGF-1 receptor when applied to cultured cells $[8,22]$. Although the mechanism for this activity remains to be determined, it is possible that secreted Klotho protein may modify glycans of the insulin/IGF-1 receptors, which inhibits their activity and/or alters cell surface abundance. Of note, it has been known for decades that treatment of cultured cells with sialidase induces insulin resistance [70]. In addition, transgenic mice that overexpress a sialidase (NEU3) on the cell surface develop glucose intolerance due to increased insulin resistance[71]. These observations suggest a potential link between insulin resistance and removal of cell surface sialic acids.

The ability of Klotho to inhibit insulin/IGF-1 signaling may be associated with anti-aging properties of Klotho, since numerous lines of genetic evidence indicate that moderate inhibition of insulin-like signaling pathway is one of the evolutionarily conserved mechanisms for suppressing aging [72]. Recent studies have shown that increased insulin resistance does not necessarily mean diabetes and short life span. Rather, it has become increasingly clear that adequate suppression of insulin-like signaling pathway is an evolutionarily conserved mechanism for anti-aging and life span extension. Reduction-of-function mutations in the genes encoding orthologs of insulin receptor, insulin receptor substrates (IRS), and PI3-kinase has been known to extend life span in C elegans and Drosophila [73-77]. In mammals, increased longevity is reported in mice lacking insulin receptor in adipose tissues [78], mice heterozygous for a null allele of the insulin-like growth factor-1 (IGF-1) receptor gene [79], mice lacking IRS-1 [80], mice lacking IRS-2 in the brain [81], and dwarf mice with impaired growth hormone (GH)-IGF-1 endocrine axis [23-25]. In humans, some centenarians show resistance to IGF-1, short statue, and high serum IGF-1 associated with loss-of-function mutations in the IGF-1 receptor gene [82]. Importantly, some long-lived animals exhibit insulin resistance [80], indicating that increased insulin sensitivity is not a prerequisite for long life span and anti-aging. Although many long-lived animals indeed exhibit increased insulin sensitivity, it is always associated with hypoinsulinemia and attenuated insulin/IGF-1 signaling activity in tissues. Thus, attenuated insulin/IGF-1 signaling activity in tissues shows closer association with life span extension than increased insulin sensitivity, yet precise mechanism for this remains to be determined.

4.2.3. Suppression of oxidative stress-In C. elegans, life span extension by inhibiting insulin-like signaling as seen in daf-2 and age-1 mutants is dependent on a forkhead transcription factor daf-16 [83]. Forkhead transcription factors are negatively regulated by insulin-like signaling, suggesting that their activation plays a critical role in the suppression of aging caused by insulin-like signaling inhibition. The mammalian homologs of daf-16 are Forkhead box O (FOXO) transcription factors, FOXO1, FOXO3a, and FOXO4. These FOXOs are also negatively regulated by insulin/IGF-1 signaling [84]: Activation of insulin/IGF-1 signaling increases activity of a serine-threonine kinase Akt, which in turn phosphorylates FOXOs. Phosphorylated FOXOs are excluded from nucleus and unable to function as transcription factors. FOXOs up-regulate expression of multiple target genes, including antioxidant enzymes such as catalase and mitochondrial manganese-superoxide dismutase (SOD2) [85]. Catalase and SOD2 detoxify harmful reactive oxygen species (ROS) hydrogen peroxide and superoxide, respectively, and reduce oxidative stress. Thus, activation of FOXOs by inhibiting insulin/IGF-1 signaling can increase cellular protection against oxidative stress and may contribute to the suppression of aging. 
Klotho-overexpressing transgenic mice have higher SOD2 expression in muscles and less phosphorylated FOXOs than wild-type mice, associated with less oxidative stress as evidenced by lower levels of urinary 8-OHdG, a marker of oxidative damages to DNA [86]. In addition, Klotho-overexpressing transgenic mice survive a sub-lethal dose of paraquat, an herbicide that generates superoxide, significantly longer than wild-type mice, indicating that Klotho overexpression induces resistance to oxidative stress. Furthermore, treatment of cultured cells with the secreted Klotho protein inhibits insulin/IGF-1 signaling, activates FOXOs, induces SOD2 expression, and reduces oxidative damages and apoptosis induced by paraquat [86] or hydrogen peroxide [87]. It remains to be determined whether the ability of Klotho to reduce oxidative stress primarily depends on up-regulation of anti-oxidant enzymes.

Oxidative stress is involved in the pathogenesis of various disease conditions including ischemia and inflammation. If Klotho can alleviate oxidative stress, Klotho may protect tissues from ischemia and inflammation. Expression of Klotho was significantly suppressed in the kidney subjected to experimental ischemic-reperfusion injury. However, adenovirus-mediated transduction of Klotho expression prevented the ischemic renal damages and the development of acute renal failure [88]. In another report, transgenic over-expression of Klotho in a mouse model of glomerulomephritis restored mitochondrial function and suppressed mitochondrial DNA damage in the kidney. It also suppressed accelerated cellular senescence and apoptosis associated with glomerulonephritis, resulting in preservation of renal function and improvement of survival [89]. These observations suggest that Klotho may induce resistance to oxidative stress and protect tissues from oxidative damages.

4.2.4. Nitric oxide production-Nitric oxide (NO) is involved in the regulation of vascular tone. Endothelium-dependent vasodilation in response to acetylcholine is attenuated in aorta and arterioles from Klotho-deficient mice, indicating that Klotho deficiency causes a reduction of NO synthesis in vascular endothelial cells [90]. Consistent with this finding, Klothodeficient mice exhibit impaired angiogenesis, which is dependent on endothelium-derived NO [91]. Systemic NO synthesis is also reduced in Klotho-deficient mice as determined by urinary excretion of NO metabolites [90]. Importantly, defects in NO synthesis observed in Klothodeficient mice are not secondary to hyperphosphatemia or hypervitaminosis D. because klotho heterozygous mice with normal blood phosphate and vitamin D levels have moderate defects in NO synthesis as well. Furthermore, parabiosis (surgical connection of two animals to allow exchange of humoral factors) between klotho heterozygous mice and wild-type mice restores acetylcholine-induced vasodilation in klotho heterozygous mice, indicating involvement of a humoral factor(s) in the activity of Klotho protein that maintains NO synthesis [90]. In addition, in vivo Klotho gene delivery using an adenoviral expression vector increases endothelium-dependent NO synthesis in a rat model of multiple atherogenic risk factors [92]. The mechanism for regulation of NO synthesis by Klotho remains to be determined.

4.2.5. Suppression of Wnt signaling-It was recently reported that secreted Klotho protein bound to multiple Wnt ligands and inhibited their ability to activate Wnt signaling, potentially through preventing Wnt binding to its cognate cell-surface receptor [93]. Although activation of Wnt signaling is essential for stem cells to proliferate and survive, continuous activation of Wnt signaling can cause rapid exhaustion and depletion of stem cells [94,95]. Since stem cell dysfunction limits tissue regeneration and potentially affects aging processes, the ability of secreted Klotho protein to inhibit Wnt signaling may contribute to aging-like phenotypes in Klotho-deficient mice. The skin from Klotho-deficient mice has a reduced number of epidermal stem cells within the hair follicles. These epidermal stem cells exhibit higher Wnt signaling activity and higher expression of an endogenous cell-senescence marker (SA $\beta$-galactosidase) than those in wild-type mice, suggesting that Klotho deficiency caused continuous activation of Wnt signaling and senescence of stem cells. The reduced number of epidermal stem cells may also explain impairment of wound healing in Klotho-deficient mice. 
The bone phenotype in Klotho-deficient mice $[14,96]$ may be partly attributed to the altered Wnt signaling as well. Klotho-deficient mice exhibit reduced cortical bone thickness associated with paradoxically increased trabecular bone at the metaphysis of tibia, where Wnt signaling is selectively enhanced when compared with wild-type mice. Since Wnt signaling promotes proliferation/survival of osteoblasts, the selective enhancement of Wnt signaling may explain why Klotho-deficient mice have increased bone only in the trabecular bone.

It was reported that $\mu$-calpain, a calcium-dependent protease that cleaves various cellular proteins including $\beta$-catenin, was significantly activated in tissues from Klotho-deficient mice [97]. Activation of Wnt signaling induces accumulation of cytoplasmic $\beta$-catenin, which in turn translocates into nucleus and interacts with transcription factors of the T cell factor (TCF) family to regulate expression of their target genes. Although the cytoplasmic $\beta$-catenin is primarily degraded by ubiquitination followed by proteasomal degradation, recent studies have indicated that calpain, activated by calcium release from intracellular stores, also participates in $\beta$-catenin degradation [98]. Activation of calpain in Klotho-deficient mice may be a secondary response to augmented Wnt signaling in these animals. $\beta$-catenin can bind not only to TCFs but also to FOXOs and enhances their transcriptional activity [99]. The interaction between $\beta$-catenin and FOXOs is enhanced in cells under oxidative stress, which potentially shifts $\beta$-catenin from TCFs to FOXOs and induces cell cycle arrest and DNA repair [100]. Understanding of the relation between Klotho, oxidative stress, FOXO, and $\beta$-catenin may be a new target of research in aging, cancer, and stem cell biology.

4.2.6. Klotho as a suppressor of breast cancer-Ample clinical and laboratory data indicate a critical role for insulin/IGF-1 signaling in breast cancer. Notably: 1) increased serum insulin levels are associated with adverse prognosis in breast cancer [101]; 2) High circulating IGF-1 levels are associated with increased risk of pre-menopausal breast cancer [102]; and 3) Inhibition of insulin/IGF-1 signaling inhibits growth of breast cancer cells [103]. Since secreted Klotho protein inhibits activation of insulin/IGF-1 receptors, Klotho may function as a suppressor of breast cancer. Consistent with this notion, immunohistochemical analysis of human breast tissue arrays showed that normal breast epithelial cells express Klotho protein, whereas its expression is significantly decreased or lost in ductal carcinoma in situ and invasive ductal carcinoma [8]. In addition, several lines of experimental evidence support the notion that Klotho functions as a tumor suppressor. 1) Forced expression of Klotho in breast cancer cell lines reduces their proliferation. 2) Knock-down of endogenous Klotho expression in MCF-7 breast cancer cells promotes their proliferation. 3) Forced expression of Klotho in MCF-7 cells attenuates IGF-1-induced phosphorylation of the IGF-1 receptor, IRS-1, AKT1, and ERK. Similar effects were observed when MCF-7 cells are treated with recombinant secreted Klotho protein. 4) Knock-down of endogenous Klotho in MCF-7 cells enhanced IGF-1-induced AKT phosphorylation. 5) Inhibition of IGF-1 signaling by Klotho increased expression of CCAAT/enhancer-binding proteins (C/EBP) [8]. These transcription factors are known to be down-regulated by IGF-1 and identified as breast cancer growth suppressors [104]. All these observations are consistent with the hypothesis that Klotho may be a suppressor of breast cancer. It remains to be determined whether the anti-breast cancer activity of Klotho depends primarily on its ability to suppress IGF-1 signaling or on other unknown mechanisms.

4.2.7. Human KLOTHO gene polymorphism and mutations-A functional variant of human Klotho protein contains six sequence variations in complete linkage disequilibrium, two of which result in amino acid substitutions F352V and C370S. The F (phenylalanine) at this position is highly conserved among $\beta$-glucosidases of various species and its substitution to $\mathrm{V}$ (valine) may alter the excretion and enzymatic activity of the protein [105]. Interestingly, heterozygotes for this variant have advantage for longevity, while homozygotes are disadvantageous for survival, because homozygotes are significantly under-represented in the aged [105]. In contrast, heterozygotes have longer life span than wild-types in multiple 
populations, suggesting that the $K L O T H O$ gene variation affects human life span. In addition, homozygosity of this variant is associated with traditional cardiovascular risk factors including low high-density lipoprotein cholesterol and high systolic blood pressure and newly identified as an independent risk factor for stroke and early-onset coronary artery disease. In contrast, heterozygosity is associated with lower risk for stroke and coronary artery disease, which is consistent with its association with long life span [106,107]. In addition to this KLOTHO variant, several single-nucleotide polymorphisms (SNPs) are associated with bone mineral density [108-111], glucose metabolism [112], and cognitive function [113]

Recently, two patients carrying mutations in the $K L O T H O$ gene were reported. One is a 13year-old girl who exhibits soft tissue and vascular calcification with elevated blood phosphate, calcium, vitamin D, and FGF23 levels, and carries a loss-of-function mutation in the KLOTHO gene (H193R) [114]. The mutant Klotho protein has reduced ability to form a stable complex with FGF receptors. Although the patient has already been prescribed with low phosphate diet and phosphate binders and exhibits no other features of premature aging, followup of this patient may provide valuable information about effects of Klotho on age-sensitive traits in humans. The other is a 23-year-old female patient with hypophosphatemic rickets and hyperparathyroidism. She has a translocation with a breakpoint adjacent to the KLOTHO gene, which is associated with an increased serum level of secreted Klotho protein. It remains to be determined why the high serum Klotho level causes hyperparathyroidism.

\section{Concluding remarks}

The discovery of the klotho gene has led to identification of multiple novel endocrine axes mediated by endocrine FGFs and Klothos that regulates various metabolic processes. The transmembrane form of Klotho protein functions as a co-receptor for FGF23 and regulates phosphate, calcium, and vitamin D metabolism. The extracellular domain of Klotho protein is shed and secreted into the systemic circulation where it functions as an endocrine factor. The secreted Klotho protein controls multiple ion channels and growth factor signaling pathways including insulin, IGF-1, and Wnt, potentially participating in biology of cancer and stem cells. Identification of the common molecular basis for these multiple function of Klotho will be of particular importance to understand the anti-aging properties of Klotho.

\section{References}

1. Kuro-o M, Matsumura Y, Aizawa H, et al. Mutation of the mouse klotho gene leads to a syndrome resembling ageing. Nature 1997;390:45-51. [PubMed: 9363890]

2. Kuro-o M, Hanaoka K, Hiroi Y, et al. Salt-sensitive hypertension in transgenic mice overexpressing $\mathrm{Na}(+)$-proton exchanger. Circ Res 1995;76:148-153. [PubMed: 8001273]

3. Matsumura Y, Aizawa H, Shiraki-Iida T, Nagai R, Kuro-o M, Nabeshima Y. Identification of the human klotho gene and its two transcripts encoding membrane and secreted klotho protein. Biochem Biophys Res Commun 1998;242:626-630. [PubMed: 9464267]

4. Shiraki-Iida T, Aizawa H, Matsumura Y, et al. Structure of the mouse klotho gene and its two transcripts encoding membrane and secreted protein. FEBS Lett 1998;424:6-10. [PubMed: 9537505]

5. Mian IS. Sequence, structural, functional, and phylogenetic analyses of three glycosidase families. Blood Cells Mol Dis 1998;24:83-100. [PubMed: 9779294]

6. Ben-Dov IZ, Galitzer H, Lavi-Moshayoff V, et al. The parathyroid is a target organ for FGF23 in rats. J Clin Invest 2007;117:4003-4008. [PubMed: 17992255]

7. Kamemori M, Ohyama Y, Kurabayashi M, Takahashi K, Nagai R, Furuya N. Expression of Klotho protein in the inner ear. Hear Res 2002;171:103-110. [PubMed: 12204354]

8. Wolf I, Levanon-Cohen S, Bose S, et al. Klotho: a tumor suppressor and a modulator of the IGF-1 and FGF pathways in human breast cancer. Oncogene 2008;27:7094-7105. [PubMed: 18762812] 
9. Tsujikawa H, Kurotaki Y, Fujimori T, Fukuda K, Nabeshima Y. Klotho, a gene related to a syndrome resembling human premature aging, functions in a negative regulatory circuit of vitamin $\mathrm{D}$ endocrine system. Mol Endocrinol 2003;17:2393-2403. [PubMed: 14528024]

10. Toyama R, Fujimori T, Nabeshima Y, Itoh Y, Tsuji Y, Osamura RY. Impaired regulation of gonadotropins leads to the atrophy of the female reproductive system in klotho-deficient mice. Endocrinology 2006;147:120-129. [PubMed: 16179415]

11. Min D, Panoskaltsis-Mortari A, Kuro-o M, Hollander GA, Blazar BR, Weinberg KI. Sustained thymopoiesis and improvement in functional immunity induced by exogenous KGF administration in murine models of aging. Blood 2007;109:2529-2537. [PubMed: 17138819]

12. Yoshida T, Fujimori T, Nabeshima Y. Mediation of unusually high concentrations of 1,25dihydroxyvitamin D in homozygous klotho mutant mice by increased expression of renal 1alphahydroxylase gene. Endocrinology 2002;143:683-689. [PubMed: 11796525]

13. Kawaguchi H, Manabe N, Miyaura C, Chikuda H, Nakamura K, Kuro-o M. Independent impairment of osteoblast and osteoclast differentiation in klotho mouse exhibiting low-turnover osteopenia. J Clin Invest 1999;104:229-237. [PubMed: 10430604]

14. Yamashita T, Nifuji A, Furuya K, Nabeshima Y, Noda M. Elongation of the epiphyseal trabecular bone in transgenic mice carrying a klotho gene locus mutation that leads to a syndrome resembling aging. J Endocrinol 1998;159:1-8. [PubMed: 9795335]

15. Yamashita T, Yamashita M, Noda M, Nabeshima Y. High-resolution microcomputed tomography analyses of the abnormal trabecular bone structures in klotho gene mutant mice. J Endocrinol 2000;164:239-245. [PubMed: 10657859]

16. Suga T, Kurabayashi M, Sando Y, et al. Disruption of the klotho gene causes pulmonary emphysema in mice. Defect in maintenance of pulmonary integrity during postnatal life. Am J Respir Cell Mol Biol 2000;22:26-33. [PubMed: 10615062]

17. Sato A, Hirai T, Imura A, et al. Morphological mechanism of the development of pulmonary emphysema in klotho mice. Proc Natl Acad Sci U S A 2007;104:2361-2365. [PubMed: 17284608]

18. Nagai T, Yamada K, Kim HC, et al. Cognition impairment in the genetic model of aging klotho gene mutant mice: a role of oxidative stress. Faseb J 2003;17:50-52. [PubMed: 12475907]

19. Anamizu Y, Kawaguchi H, Seichi A, et al. Klotho insufficiency causes decrease of ribosomal RNA gene transcription activity, cytoplasmic RNA and rough ER in the spinal anterior horn cells. Acta Neuropathol (Berl) 2005;109:457-466. [PubMed: 15834732]

20. Lin MT, Beal MF. Mitochondrial dysfunction and oxidative stress in neurodegenerative diseases. Nature 2006;443:787-795. [PubMed: 17051205]

21. Utsugi T, Ohno T, Ohyama Y, et al. Decreased insulin production and increased insulin sensitivity in the klotho mutant mouse, a novel animal model for human aging. Metabolism 2000;49:1118-1123. [PubMed: 11016890]

22. Kurosu H, Yamamoto M, Clark JD, et al. Suppression of Aging in Mice by the Hormone Klotho. Science 2005;309:1829-1833. [PubMed: 16123266]

23. Brown-Borg HM, Borg KE, Meliska CJ, Bartke A. Dwarf mice and the ageing process [letter]. Nature 1996;384:33. [PubMed: 8900272]

24. Flurkey K, Papaconstantinou J, Harrison DE. The Snell dwarf mutation Pit1(dw) can increase life span in mice. Mech Ageing Dev 2002;123:121-130. [PubMed: 11718806]

25. Bartke A, Brown-Borg H. Life extension in the dwarf mouse. Curr Top Dev Biol 2004;63:189-225. [PubMed: 15536017]

26. Masuda H, Chikuda H, Suga T, Kawaguchi H, Kuro-o M. Regulation of multiple ageing-like phenotypes by inducible klotho gene expression in klotho mutant mice. Mech Ageing Dev 2005;126:1274-1283. [PubMed: 16144705]

27. Duce JA, Podvin S, Hollander W, Kipling D, Rosene DL, Abraham CR. Gene profile analysis implicates Klotho as an important contributor to aging changes in brain white matter of the rhesus monkey. Glia 2008;56:106-117. [PubMed: 17963266]

28. Chen CD, Podvin S, Gillespie E, Leeman SE, Abraham CR. Insulin stimulates the cleavage and release of the extracellular domain of Klotho by ADAM10 and ADAM17. Proc Natl Acad Sci U S A 2007;104:19796-19801. [PubMed: 18056631] 
29. Imura A, Iwano A, Tohyama O, et al. Secreted Klotho protein in sera and CSF: implication for posttranslational cleavage in release of Klotho protein from cell membrane. FEBS Lett 2004;565:143147. [PubMed: 15135068]

30. Schiavi SC, Kumar R. The phosphatonin pathway: new insights in phosphate homeostasis. Kidney Int 2004;65:1-14. [PubMed: 14675031]

31. Dusso AS, Brown AJ, Slatopolsky E. Vitamin D. Am J Physiol Renal Physiol 2005;289:F8-28. [PubMed: 15951480]

32. Berndt T, Kumar R. Phosphatonins and the regulation of phosphate homeostasis. Annu Rev Physiol 2007;69:341-359. [PubMed: 17002592]

33. Kuro-o M. Klotho as a regulator of fibroblast growth factor signaling and phosphate/calcium metabolism. Curr Opin Nephrol Hypertens 2006;15:437-441. [PubMed: 16775459]

34. White KE, Evans WE, O'Rlordan JLH, et al. Autosomal dominant hypophosphataemic rickets is associated with mutations in FGF23. Nat Genet 2000;26:345-348. [PubMed: 11062477]

35. Quarles LD. FGF23, PHEX, and MEPE regulation of phosphate homeostasis and skeletal mineralization. Am J Physiol Endocrinol Metab 2003;285:E1-9. [PubMed: 12791601]

36. Saito H, Maeda A, Ohtomo S, et al. Circulating FGF-23 is regulated by 1alpha,25-dihydroxyvitamin D3 and phosphorus in vivo. J Biol Chem 2005;280:2543-2549. [PubMed: 15531762]

37. Liu S, Tang W, Zhou J, et al. Fibroblast growth factor 23 is a counter-regulatory phosphaturic hormone for vitamin D. J Am Soc Nephrol 2006;17:1305-1315. [PubMed: 16597685]

38. Liu S, Gupta A, Quarles LD. Emerging role of fibroblast growth factor 23 in a bone-kidney axis regulating systemic phosphate homeostasis and extracellular matrix mineralization. Curr Opin Nephrol Hypertens 2007;16:329-335. [PubMed: 17565275]

39. Shimada T, Kakitani M, Yamazaki Y, et al. Targeted ablation of Fgf23 demonstrates an essential physiological role of FGF23 in phosphate and vitamin D metabolism. J Clin Invest 2004;113:561568. [PubMed: 14966565]

40. Yu X, White KE. FGF23 and disorders of phosphate homeostasis. Cytokine Growth Factor Rev 2005;16:221-232. [PubMed: 15863037]

41. Yu X, Ibrahimi OA, Goetz R, et al. Analysis of the Biochemical Mechanisms for the Endocrine Actions of Fibroblast Growth Factor-23. Endocrinology 2005;146:4647-4656. [PubMed: 16081635]

42. Zhang X, Ibrahimi OA, Olsen SK, Umemori H, Mohammadi M, Ornitz DM. Receptor specificity of the fibroblast growth factor family. The complete mammalian FGF family. J Biol Chem 2006;281:15694-15700. [PubMed: 16597617]

43. Kurosu H, Ogawa Y, Miyoshi M, et al. Regulation of fibroblast growth factor-23 signaling by klotho. J Biol Chem 2006;281:6120-6123. [PubMed: 16436388]

44. Urakawa I, Yamazaki Y, Shimada T, et al. Klotho converts canonical FGF receptor into a specific receptor for FGF23. Nature 2006;444:770-774. [PubMed: 17086194]

45. Krajisnik T, Bjorklund P, Marsell R, et al. Fibroblast growth factor-23 regulates parathyroid hormone and 1alpha-hydroxylase expression in cultured bovine parathyroid cells. J Endocrinol 2007;195:125131. [PubMed: 17911404]

46. Shimada T, Hasegawa H, Yamazaki Y, et al. FGF-23 is a potent regulator of vitamin D metabolism and phosphate homeostasis. J Bone Miner Res 2004;19:429-435. [PubMed: 15040831]Epub 2003 Dec 2029

47. Hesse M, Frohlich LF, Zeitz U, Lanske B, Erben RG. Ablation of vitamin D signaling rescues bone, mineral, and glucose homeostasis in Fgf-23 deficient mice. Matrix Biol 2007;26:75-84. [PubMed: 17123805]

48. Morishita K, Shirai A, Kubota M, et al. The progression of aging in klotho mutant mice can be modified by dietary phosphorus and zinc. J Nutr 2001;131:3182-3188. [PubMed: 11739863]

49. Segawa H, Yamanaka S, Ohno Y, et al. Correlation between hyperphosphatemia and type II Na-Pi cotransporter activity in klotho mice. Am J Physiol Renal Physiol 2007;292:F769-779. [PubMed: 16985213]

50. Razzaque MS, Sitara D, Taguchi T, St-Arnaud R, Lanske B. Premature aging-like phenotype in fibroblast growth factor 23 null mice is a vitamin D-mediated process. Faseb J 2006;20:720-722. [PubMed: 16436465] 
51. Stubbs JR, Liu S, Tang W, et al. Role of Hyperphosphatemia and 1,25-Dihydroxyvitamin D in Vascular Calcification and Mortality in Fibroblastic Growth Factor 23 Null Mice. J Am Soc Nephrol 2007;18:2116-2124. [PubMed: 17554146]

52. Medici D, Razzaque MS, Deluca S, et al. FGF-23-Klotho signaling stimulates proliferation and prevents vitamin D-induced apoptosis. J Cell Biol 2008;182:459-465. [PubMed: 18678710]

53. Itoh N, Ornitz DM. Evolution of the Fgf and Fgfr gene families. Trends Genet 2004;20:563-569. [PubMed: 15475116]

54. Inagaki T, Choi M, Moschetta A, et al. Fibroblast growth factor 15 functions as an enterohepatic signal to regulate bile acid homeostasis. Cell Metab 2005;2:217-225. [PubMed: 16213224]

55. Choi M, Moschetta A, Bookout AL, et al. Identification of a hormonal basis for gallbladder filling. Nat Med 2006;12:1253-1255. [PubMed: 17072310]

56. Kharitonenkov A, Shiyanova TL, Koester A, et al. FGF-21 as a novel metabolic regulator. J Clin Invest 2005;115:1627-1635. [PubMed: 15902306]

57. Inagaki T, Dutchak P, Zhao G, et al. Endocrine Regulation of the Fasting Response by PPARalphaMediated Induction of Fibroblast Growth Factor 21. Cell Metab 2007;5:415-425. [PubMed: 17550777]

58. Ito S, Kinoshita S, Shiraishi N, et al. Molecular cloning and expression analyses of mouse betaklotho, which encodes a novel Klotho family protein. Mech Dev 2000;98:115-119. [PubMed: 11044614]

59. Kurosu H, Choi M, Ogawa Y, et al. Tissue-specific expression of betaKlotho and fibroblast growth factor (FGF) receptor isoforms determines metabolic activity of FGF19 and FGF21. J Biol Chem 2007;282:26687-26695. [PubMed: 17623664]

60. Ito S, Fujimori T, Furuya A, Satoh J, Nabeshima Y, Nabeshima Y. Impaired negative feedback suppression of bile acid synthesis in mice lacking betaKlotho. J Clin Invest 2005;115:2202-2208. [PubMed: 16075061]

61. Yu C, Wang F, Kan M, et al. Elevated cholesterol metabolism and bile acid synthesis in mice lacking membrane tyrosine kinase receptor FGFR4. J Biol Chem 2000;275:15482-15489. [PubMed: 10809780]

62. Kurosu H, Kuro-o M. The Klotho gene family and the endocrine fibroblast growth factors. Mol Cell Endocrinol. 2008

63. Kurosu H, Kuro-o M. The Klotho gene family and the endocrine fibroblast growth factors. Curr Opin Nephrol Hypertens 2008;17:368-372. [PubMed: 18660672]

64. Kuro-o M. Endocrine FGFs and Klothos: emerging concepts. Trends Endocrinol Metab 2008;19:239_ 245. [PubMed: 18692401]

65. Tohyama O, Imura A, Iwano A, et al. Klotho is a novel beta-glucuronidase capable of hydrolyzing steroid beta-glucuronides. J Biol Chem 2004;279:9777-9784. [PubMed: 14701853]

66. Cha SK, Ortega B, Kurosu H, Rosenblatt KP, Kuro-o M, Huang CL. Removal of sialic acid involving Klotho causes cell-surface retention of TRPV5 channel via binding to galectin-1. Proc Natl Acad Sci U S A 2008;105:9805-9810. [PubMed: 18606998]

67. Chang Q, Hoefs S, van der Kemp AW, Topala CN, Bindels RJ, Hoenderop JG. The beta-glucuronidase klotho hydrolyzes and activates the TRPV5 channel. Science 2005;310:490-493. [PubMed: 16239475]

68. Hoenderop JG, Nilius B, Bindels RJ. Calcium absorption across epithelia. Physiol Rev 2005;85:373422. [PubMed: 15618484]

69. Imura A, Tsuji Y, Murata M, et al. alpha-Klotho as a regulator of calcium homeostasis. Science 2007;316:1615-1618. [PubMed: 17569864]

70. Salhanick AI, Amatruda JM. Role of sialic acid in insulin action and the insulin resistance of diabetes mellitus. Am J Physiol 1988;255:E173-179. [PubMed: 3407769]

71. Sasaki A, Hata K, Suzuki S, et al. Overexpression of plasma membrane-associated sialidase attenuates insulin signaling in transgenic mice. J Biol Chem 2003;278:27896-27902. [PubMed: 12730204]

72. Tatar M, Bartke A, Antebi A. The Endocrine Regulation of Aging by Insulin-like Signals. Science 2003;299:1346-1351. [PubMed: 12610294]

73. Kenyon C. The Plasticity of Aging: Insights from Long-Lived Mutants. Cell 2005;120:449-460. [PubMed: 15734678] 
74. Kenyon C, Chang J, Gensch E, Rudner A, Tabtiang R. A C. elegans mutant that lives twice as long as wild type. Nature 1993;366:461-464. [PubMed: 8247153]

75. Morris JZ, Tissenbaum HA, Ruvkun G. A phosphatidylinositol-3-OH kinase family member regulating longevity and diapause in Caenorhabditis elegans. nature 1996;382:536-539. [PubMed: 8700226]

76. Tatar M, Kopelman A, Epstein D, Tu MP, Yin CM, Garofalo RS. A Mutant Drosophila Insulin Receptor Homolog That Extends Life-Span and Impairs Neuroendocrine Function. Science 2001;292:107-110. [PubMed: 11292875]

77. Clancy DJ, Gems D, Harshman LG, et al. Extension of Life-Span by Loss of CHICO, a Drosophila Insulin Receptor Substrate Protein. Science 2001;292:104-106. [PubMed: 11292874]

78. Bluher M, Kahn BB, Kahn CR. Extended longevity in mice lacking the insulin receptor in adipose tissue. Science 2003;299:572-574. [PubMed: 12543978]

79. Holzenberger M, Dupont J, Ducos B, et al. IGF-1 receptor regulates lifespan and resistance to oxidative stress in mice. Nature 2003;421:182-187. [PubMed: 12483226]

80. Selman C, Lingard S, Choudhury AI, et al. Evidence for lifespan extension and delayed age-related biomarkers in insulin receptor substrate 1 null mice. FASEB J 2008;22:807-818. [PubMed: 17928362]

81. Taguchi A, Wartschow LM, White MF. Brain IRS2 signaling coordinates life span and nutrient homeostasis. Science 2007;317:369-372. [PubMed: 17641201]

82. Suh Y, Atzmon G, Cho MO, et al. Functionally significant insulin-like growth factor I receptor mutations in centenarians. Proc Natl Acad Sci U S A 2008;105:3438-3442. [PubMed: 18316725]

83. Ogg S, Paradis S, Gottlieb S, et al. The Fork head transcription factor DAF-16 transduces insulinlike metabolic and longevity signals in C. elegans. Nature 1997;389:994-999. [PubMed: 9353126]

84. Brunet A, Bonni A, Zigmond MJ, et al. Akt promotes cell survival by phosphorylating and inhibiting a Forkhead transcription factor. Cell 1999;96:857-868. [PubMed: 10102273]

85. Kops GJ, Dansen TB, Polderman PE, et al. Forkhead transcription factor FOXO3a protects quiescent cells from oxidative stress. Nature 2002;419:316-321. [PubMed: 12239572]

86. Yamamoto M, Clark JD, Pastor JV, et al. Regulation of oxidative stress by the anti-aging hormone Klotho. J Biol Chem 2005;280:38029-38034. [PubMed: 16186101]

87. Ikushima M, Rakugi H, Ishikawa K, et al. Anti-apoptotic and anti-senescence effects of Klotho on vascular endothelial cells. Biochem Biophys Res Commun 2006;339:827-832. [PubMed: 16325773]

88. Sugiura H, Yoshida T, Tsuchiya K, et al. Klotho reduces apoptosis in experimental ischaemic acute renal failure. Nephrol Dial Transplant 2005;20:2636-2645. [PubMed: 16204278]

89. Haruna Y, Kashihara N, Satoh M, et al. Amelioration of progressive renal injury by genetic manipulation of Klotho gene. Proc Natl Acad Sci U S A 2007;104:2331-2336. [PubMed: 17287345]

90. Saito Y, Yamagishi T, Nakamura T, et al. Klotho protein protects against endothelial dysfunction. Biochem Biophys Res Commun 1998;248:324-329. [PubMed: 9675134]

91. Shimada T, Takeshita Y, Murohara T, et al. Angiogenesis and vasculogenesis are impaired in the precocious-aging klotho mouse. Circulation 2004;110:1148-1155. [PubMed: 15302783]

92. Saito Y, Nakamura T, Ohyama Y, et al. In vivo klotho gene delivery protects against endothelial dysfunction in multiple risk factor syndrome [In Process Citation]. Biochem Biophys Res Commun 2000;276:767-772. [PubMed: 11027545]

93. Liu H, Fergusson MM, Castilho RM, et al. Augmented Wnt signaling in a mammalian model of accelerated aging. Science 2007;317:803-806. [PubMed: 17690294]

94. Scheller M, Huelsken J, Rosenbauer F, et al. Hematopoietic stem cell and multilineage defects generated by constitutive beta-catenin activation. Nat Immunol 2006;7:1037-1047. [PubMed: 16951686]

95. Kirstetter P, Anderson K, Porse BT, Jacobsen SE, Nerlov C. Activation of the canonical Wnt pathway leads to loss of hematopoietic stem cell repopulation and multilineage differentiation block. Nat Immunol 2006;7:1048-1056. [PubMed: 16951689]

96. Kawaguchi H, Manabe N, Miyaura C, Chikuda H, Nakamura K, Kuro-o M. Independent impairment of osteoblast and osteoclast differentiation in klotho mouse exhibiting low-turnover osteopenia. J Clin Invest 1999;104:229-237. [PubMed: 10430604] 
97. Manya H, Inomata M, Fujimori T, et al. Klotho protein deficiency leads to overactivation of mucalpain. J Biol Chem 2002;277:35503-35508. [PubMed: 12119304]

98. Li G, Iyengar R. Calpain as an effector of the Gq signaling pathway for inhibition of Wnt/beta catenin-regulated cell proliferation. Proc Natl Acad Sci U S A 2002;99:13254-13259. [PubMed: 12239346]

99. Essers MA, de Vries-Smits LM, Barker N, Polderman PE, Burgering BM, Korswagen HC. Functional interaction between beta-catenin and FOXO in oxidative stress signaling. Science 2005;308:11811184. [PubMed: 15905404]

100. Kops GJ, Medema RH, Glassford J, et al. Control of cell cycle exit and entry by protein kinase Bregulated forkhead transcription factors. Mol Cell Biol 2002;22:2025-2036. [PubMed: 11884591]

101. Wolf I, Sadetzki S, Gluck I, et al. Association between diabetes mellitus and adverse characteristics of breast cancer at presentation. Eur J Cancer 2006;42:1077-1082. [PubMed: 16574404]

102. Yee D. Targeting insulin-like growth factor pathways. Br J Cancer 2006;94:465-468. [PubMed: 16450000]

103. Bartucci M, Morelli C, Mauro L, Ando S, Surmacz E. Differential insulin-like growth factor I receptor signaling and function in estrogen receptor (ER)-positive MCF-7 and ER-negative MDAMB-231 breast cancer cells. Cancer Res 2001;61:6747-6754. [PubMed: 11559546]

104. Gery S, Tanosaki S, Bose S, Bose N, Vadgama J, Koeffler HP. Down-regulation and growth inhibitory role of C/EBPalpha in breast cancer. Clin Cancer Res 2005;11:3184-3190. [PubMed: 15867211]

105. Arking DE, Krebsova A, Macek M Sr, et al. Association of human aging with a functional variant of klotho. Proc Natl Acad Sci U S A 2002;99:856-861. [PubMed: 11792841]

106. Arking DE, Becker DM, Yanek LR, et al. KLOTHO Allele Status and the Risk of Early-Onset Occult Coronary Artery Disease. Am J Hum Genet 2003;72:1154-1161. [PubMed: 12669274]

107. Arking DE, Atzmon G, Arking A, Barzilai N, Dietz HC. Association between a functional variant of the KLOTHO gene and high-density lipoprotein cholesterol, blood pressure, stroke, and longevity. Circ Res 2005;96:412-418. [PubMed: 15677572]

108. Kawano K, Ogata N, Chiano M, et al. Klotho gene polymorphisms associated with bone density of aged postmenopausal women. J Bone Miner Res 2002;17:1744-1751. [PubMed: 12369777]

109. Ogata N, Matsumura Y, Shiraki M, et al. Association of klotho gene polymorphism with bone density and spondylosis of the lumbar spine in postmenopausal women. Bone 2002;31:37-42. [PubMed: 12110410]

110. Yamada Y, Ando F, Niino N, Shimokata H. Association of polymorphisms of the androgen receptor and klotho genes with bone mineral density in Japanese women. J Mol Med 2005;83:50-57. [PubMed: 15536520]Epub 2004 Nov 2004

111. Zarrabeitia MT, Hernandez JL, Valero C, et al. Klotho gene polymorphism and male bone mass. Calcif Tissue Int 2007;80:10-14. [PubMed: 17205327]

112. Rhee EJ, Oh KW, Yun EJ, et al. Relationship between polymorphisms G395A in promoter and $\mathrm{C} 1818 \mathrm{~T}$ in exon 4 of the KLOTHO gene with glucose metabolism and cardiovascular risk factors in Korean women. J Endocrinol Invest 2006;29:613-618. [PubMed: 16957409]

113. Kachiwala SJ, Harris SE, Wright AF, et al. Genetic influences on oxidative stress and their association with normal cognitive ageing. Neurosci Lett 2005;386:116-120. [PubMed: 16023289]

114. Ichikawa S, Imel EA, Kreiter ML, et al. A homozygous missense mutation in human KLOTHO causes severe tumoral calcinosis. J Clin Invest 2007;117:2692-2701. [PubMed: 17694177] 


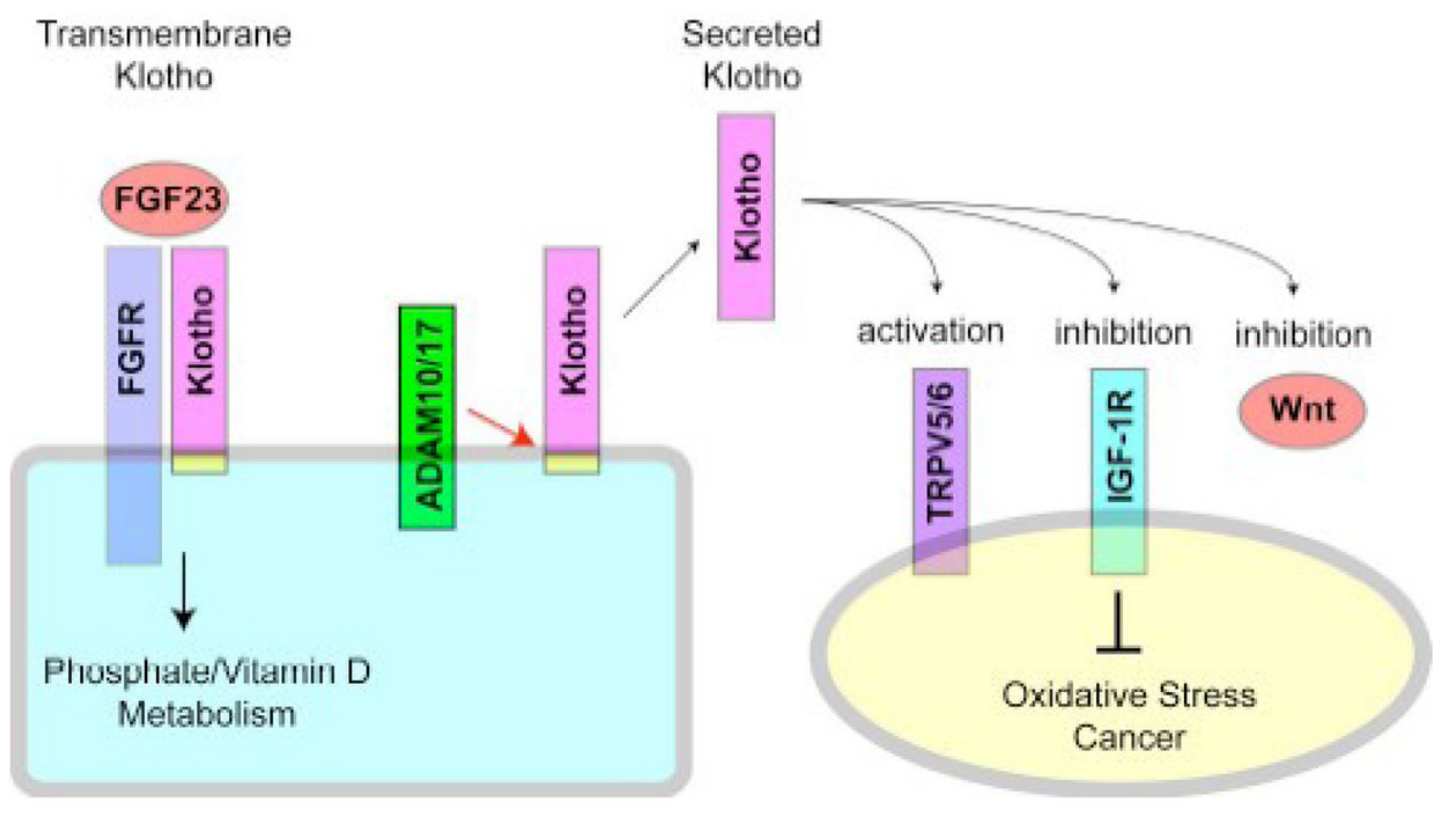

Figure 1.

Function of Klotho protein. The transmembrane Klotho forms a complex with FGF receptor (FGFR) and functions as a co-receptor for FGF23 and plays a crucial role in the regulation of phosphate and vitamin D metabolism in the kidney. On the other hand, the transmembrane Klotho is clipped by membrane-anchored proteases ADAM10 and ADAM17 just above the plasma membrane. The entire extracellular domain of Klotho is then released into blood, urine, and cerebrospinal fluid. The secreted Klotho protein has a putative sialidase activity that modifies glycans of calcium channel TRPV5 on the cell surface. A similar mechanism may explain the inhibitory effect of secreted Klotho on growth factors including insulin, IGF-1, and Wnt. The ability of secreted Klotho to inhibit IGF-1 signaling may contribute to the antioxidative stress and anti-cancer properties of Klotho. See Section 4. 


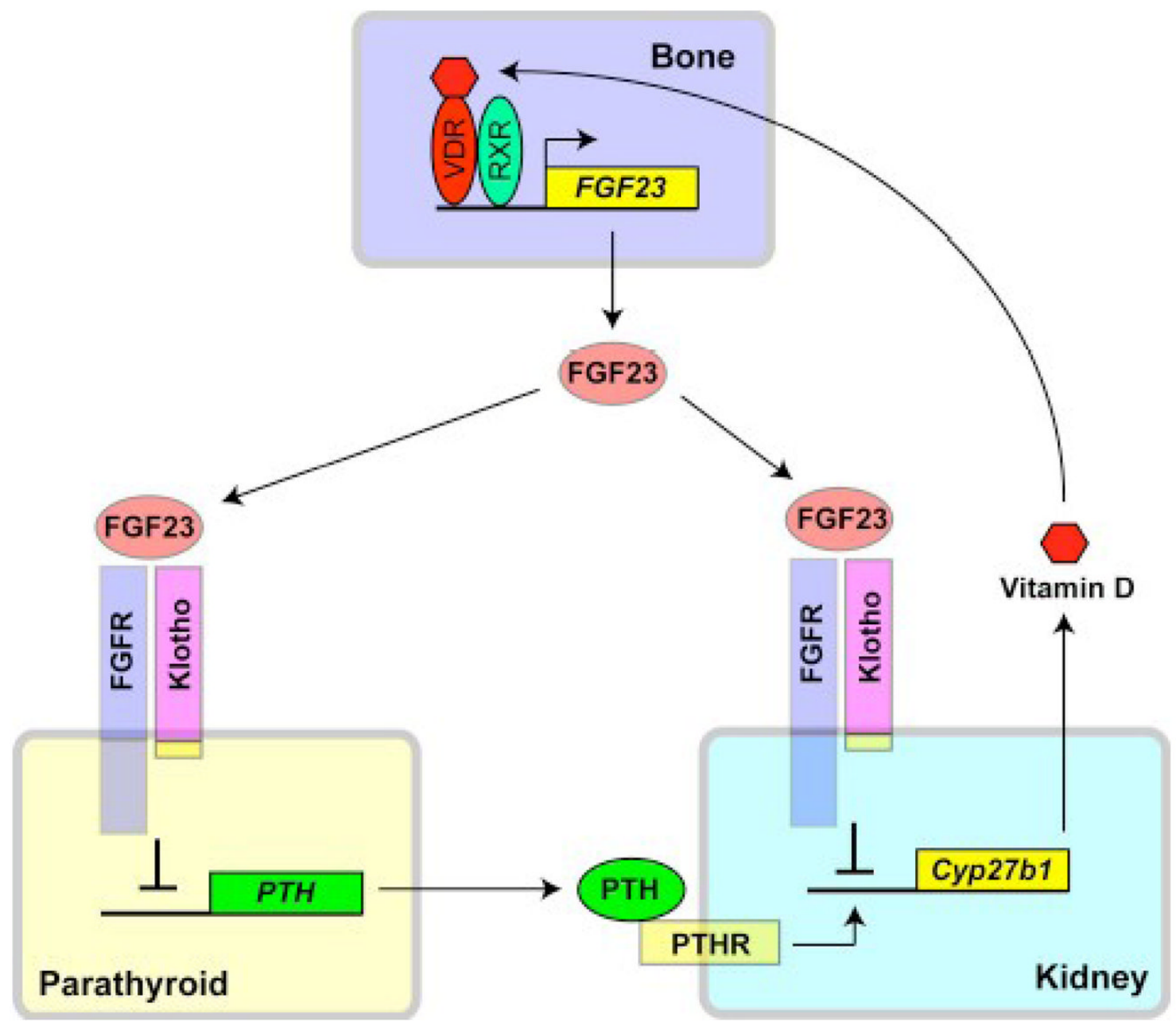

Figure 2.

Endocrine axes that regulate vitamin D metabolism mediated by FGF23 and Klotho. Active vitamin $\mathrm{D}$ (1,25-dihydroxyvitamin $\mathrm{D}_{3}$ ) binds to vitamin $\mathrm{D}$ receptor (VDR) in osteocytes, which in turn forms a heterodimer with a nuclear receptor RXR and directly binds to a promoter region of the FGF23 gene to transactivate its expression. FGF23 secreted from the bone acts on the Klotho-FGFR complex in the kidney (the bone-kidney axis) and parathyroid gland (the boneparathyroid axis). In the kidney, FGF23 suppresses expression of Cyp27b1 gene that encodes $1 \alpha$-hydroxylase and closes a negative feedback loop for vitamin D homeostasis. In the parathyroid gland, FGF23 suppresses expression of PTH. Since PTH is a potent inducer of Cyp $27 b 1$ gene expression, suppression of PTH by FGF23 reduces expression of $C y p 27 b 1$ gene as well as serum levels of 1,25-dihydroxyvitamin $\mathrm{D}_{3}$, which closes another negative feedback loop for vitamin D homeostasis. Klotho and FGF23 are indispensable for the regulation of vitamin D metabolism, because defects in either Klotho or FGF23 cause hypervitaminosis D. 


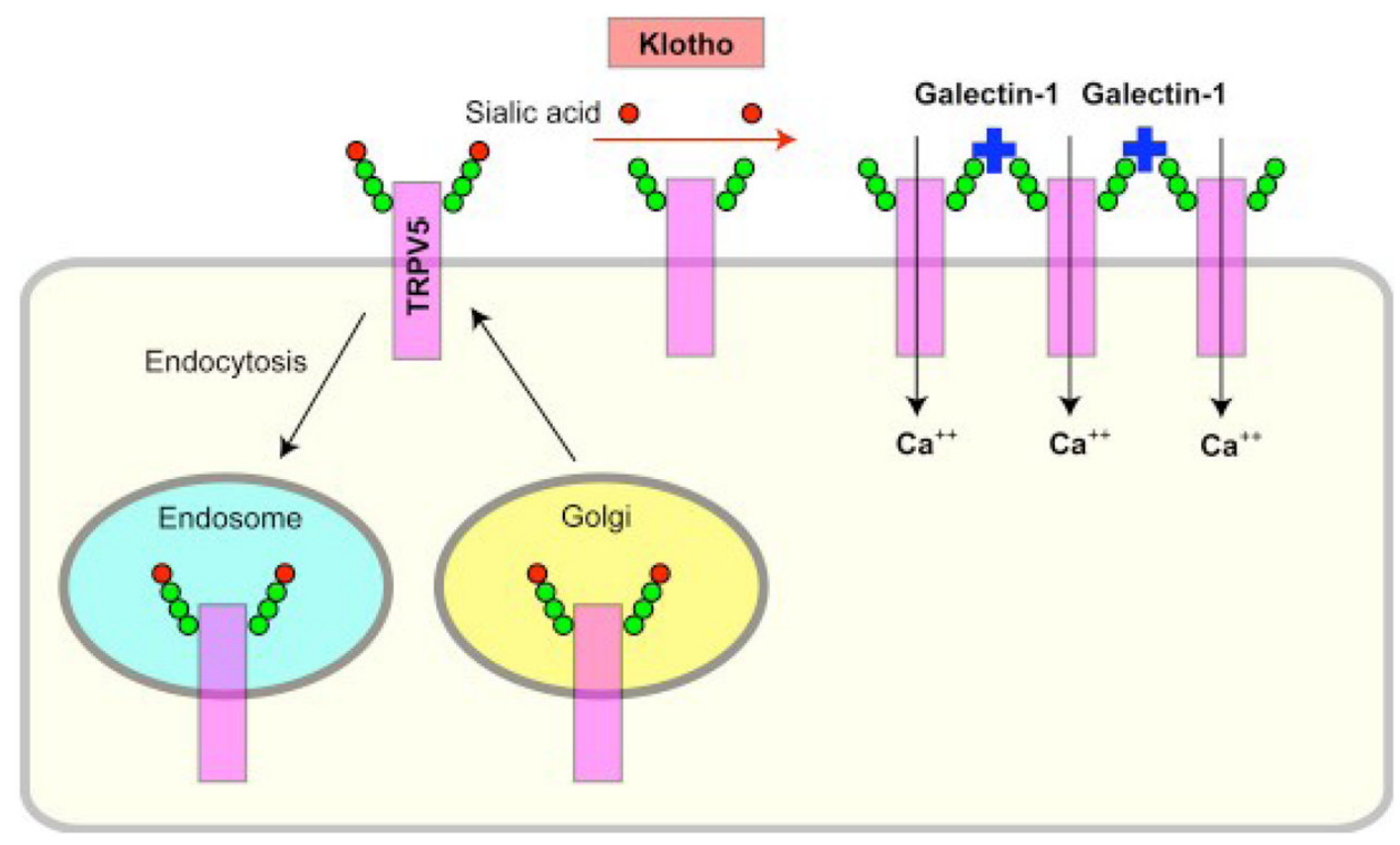

Figure 3.

Klotho activates calcium channel TRPV5. The number of TRPV5 on the plasma membrane is determined by counterbalance between insertion by protein trafficking from Golgi and removal by endocytosis to endosomes. Terminals of sugar chains of cell-surface glycoproteins are capped with sialic acids (red). Secreted Klotho protein removes these sialic acids through its putative $\alpha 2 \rightarrow 6$ sialidase activity and exposes underlying galactose residues (green) in the glycans. The exposed galactose then binds to galectin-1 (blue) in the extracellular matrix. Galectin-1 tethers TRPV5 on the cell surface and prevents its endocytosis, resulting in accumulation of TRPV5 on the plasma membrane and increase in calcium influx. 